\title{
Tradisi Mangaku Induak dalam Perkawinan di Nagari Lubuk Malako Kecamatan Sangir Jujuan Kabupaten Solok Selatan
}

\author{
Nola Apria Nengsih, Isnarmi \\ Prodi Pendidikan Pancasila dan Kewarganegaraan \\ FIS Universitas Negeri Padang \\ E-mail: nolaapria12@gmail.com
}

\section{ABSTRAK}

Penelitian ini bertujuan untuk mengetahui proses pelaksanaan mangaku induak dalam perkawinan di Nagari Lubuk Malako. Penelitian ini dilatar belakangi oleh banyak pendatang yang merasa keberatan dengan adanya tradisi mangaku induak ini karena biaya dari proses pelaksanaan yang cukup tinggi dan belum termasuk biaya pernikannya nanti. Metode yang digunakan dalam penelitian ini adalah deskriptif kualitatif dengan teknik pengumpulan data yaitu wawancara, observasi dan dokumentasi. Keabsahan data diuji dengan Triangulas sumber. Data yang telah diambil tersebut kemudian dianalisis dengan teknis analisis data yang dikemukakan oleh Miles dan Huberman yang terdiri dari tiga alur kegiatan yakni reduksi data, penyajian data dan pengambilan kesimpulan. Hasil penelitian yang didapat mengenai prosesi pelaksanaan mangaku induak yaitu (1) Prosesi sebelum pelaksanaan, dilakukan dengan mendatangi orang tua dan mamak tempat mangaku induak, mengundang ibu-ibu setempat untuk memasak hidangan yang akan dihidangkan pada malam harinya. (2) Pelaksanaan secara adat dilakukan di rumah orang tua tempat mangaku induak dengan mengundang masyarakat maupun para pemangku-pemangku adat secara pusako mudo atau disebut juga dengan perkenalan dengan yang muda-muda yang dilakukan digalanggang nan rami bersama pemuda-pemuda Lubuk Malako.

Kata Kunci: mangaku induak, tradisi, perkawinan

\begin{abstract}
This study aims to determine the process of implementing mangaku induak in marriage in Nagari Lubuk Malako. This research was motivated by many newcomers who objected to the existence of this mangaku induak tradition because the costs of the implementation process of this tradition were quite high and did not include the cost of the wedding later. The method used in this research is descriptive qualitative with data collection techniques, namely interviews, observation and documentation. The validity of the data was tested with source triangulation. The data that has been taken is then analyzed with the technical data analysis proposed by Miless and Huberman which consists of three activity lines, namely data reduction, data presentation and conclusion drawing. The research shows: The results of the research that the researcher got regarding the procession of the implementation of the mangaku induak are (1) The procession before the implementation, carried out by visiting
\end{abstract}


the parents and mamak where the mangaku induak is, inviting local mothers to cook the dishes that will be served in the evening, (2) The traditional implementation is carried out at the parents' house where the mangaku parent is invited by the community and traditional stakeholders. and in pusako mudo or also known as an introduction to the young ones which is carried out in the hemp field with the youths of Lubuk Malako.

\section{Keywords: mangaku induak, tradition, marriage}

This work is licensed under the Creative Commons Attribution-ShareAlike 4.0 International License. C2021 by author.

\section{PENDAHULUAN}

Tradisi Mangaku induak adalah salah satu tradisi yang sudah lama ada dan turun temurun dalam masyarakat dan tradisi ini adalah salah satu syarat untuk melakukan perkawinan di Nagari Lubuk Malako bagi pendatang. Hal tersebut sejalan dengan pendapat Darfian Petra, dkk (2016:1) yang menyatakan bahwa tradisi mangaku induak sebagai warisan turun temurun dalam masyarakat yang merupakan bagian dari tradisi perkawinan masyarakat apabila calon pengantin berasal dari luar nagari tersebut.

Mangaku induak berarti pendatang ingin berlindung ke salah satu suku yang ada di Nagari Lubuk Malako dan memiliki mamak sesuai dengan suku yang diminta perlindungan. Selain itu menurut Fitri Eriyanti (2016:11) setiap pendatang diharapkan oleh masyarakat nagari untuk memilih salah satu suku agar memiliki mamak dari suku di nagari tersebut sebagai tanda pendatang tersebut telah menjadi saudara masyarakat setempat. Namun pendatang dilarang memilih suku yang sama dengan calon istrinya karena di nagari Lubuk Malako perkawinan sasuku dilarang oleh adat.

Di Nagari Lubuk Malako ada 7 buah suku yang dapat dijadikan tempat Mangaku induak. Masingmasing suku tersebut dipimpin oleh Datuak-datuak yang telah diwarisi gelar (Sako) secara turun temurun, suku-suku tersebut yaitu suku Malayu Kampuang Dalam, Malayu Sigintiw, Malayu Darek, Tigo Lareh, Kampai, Panai, Panai Lundang. Tradisi mangaku induak dijadikan sebagai syarat pernikahan bagi pendatang. Jika pendatang ingin menikah dengan perempuan yang berasal dari nagari Lubuk Malako maka pendatang wajib melakukan mangaku induak. Namun jika pendatang tidak mangaku induak maka pernikahan tidak bisa dilaksanakan di nagari Lubuk Malako karena pendatang tidak memiliki niniak mamak yang akan mengurusi pernikahannya.

Penelitian ini dilatar belakangi oleh banyak pendatang yang merasa keberatan dengan adanya tradisi mangaku induak ini karena biaya dari proses pelaksanaan mangaku induak yang cukup tinggi dan belum termasuk biaya pernikahannya nanti. 
Sehingga peneliti tertarik untuk melakukan penelitian ini.

Diantara penelitian terdahulu yang memiliki kesamaan dengan penelitian ini yaitu Penelitian yang dilakukan oleh Darfian Petra, Nurharmi, dan Yusrizal dengan judul Tradisi Mangaku induak dan Manimbang Salah dalam Perkawinan di Nagari Taratak Baru Kecamatan Tanjung Gadang Kabupaten Sijunjung. Dalam penelitian ini dijelaskan bahwa tradisi ini memberikan perlindungan terhadap perempuan yang ada di Nagari Taratak Baru yang menikah dengan masyarakat yang tidak berasal dari Taratak Baru, selain itu tradisi ini mempunyai nilai-nilai kekeluargaan sekaligus dapat menyambung tali silaturrahmi yang sangat dianjurkan dalam islam.

Selain itu penelitian yang dilakukan oleh Eriyanti (2009) yang berjudul Malakok suatu mekanisme pendamai ala Minangkabau. Penelitian ini membahas tentang tatacara, persyaratan dan esensi malakok sebagai mekanisme pendamai. Selanjutnya penelitian yang dilakukan oleh Hafizah (2017) dengan judul malakok sebagai syarat untuk menjadi warga masyarakat di Nagari Tanjung Sani Kabupaten Agam. Penelitian ini memfokuskan tentang makna, syarat, dan proses malakok bagi warga berasal dari luar nagari Tanjung Sani serta konflik yang terjadi jika tidak malakok di Nagari Tanjung Sani, Kabupaten Agam.

Selain itu dalam penelitian Leny Syafyahya (2016) yang berjudul malakok sebagai dasar integrasi oleh etnis Minangkabau di Kabupaten Dharmasraya Provinsi Sumatra Barat, dijelaskan bahwa dengan melakukan malakok, maka pihak yang tidak bersuku akan mendapatkan persukuan, lalu dalam penelitian ini juga dijelaskan mengenai proses dan makna Malakok.

Selanjutnya penelitian yang dilakukan oleh Zahratul Atiqah (2019) dengan judul Tradisi Malakok dan Implikasinya terhadap Kehidupan Sosial Masyarakat Tambun Ijuak Kecamatan Payakumbuh Kabupaten 50 Kota. Dalam penelitian ini juga dijelaskan mengenai beberapa prosedur yang dilaksanakan oleh kaum pendatang untuk bisa melaksanakan proses Malakok. Selain itu dalam penelitian ini juga menjelaskan tentang implikasi malakok terhadap kehidupan masyarakat lokal dan kaum pendatang, sehingga menimbulkan dampak positif dan negatif terhadap masyarakat.

\section{METODE PENELITIAN}

Penelitian ini menggunakan penelitian kualitatif, yang merupakan sebuah penelitian yang akan menghasilkan data deskriptif dengan tujuan untuk memberikan gambaran tentang tradisi mangaku induak dalam perkawinan di Nagari Lubuk Malako.

Informan dalam penelitian ini adalah Tokoh Masyarakat, Pendatang yang telah melakukan mangaku induak dalam perkawinan, istri pendatang, Orang tua tempat mangaku induak, Masyarakat dan Wali Nagari. Jenis data yang digunakan dalam penelitian ini adalah data primer dan data sekunder. Data primer merupakan data yang didapat dari wawancara dengan informan secara langsung. Data sekunder merupakan data yang diperoleh dari dokumen-dokumen resmi dari kantor pemerintahan 
nagari, dan foto-foto yang didapat dari masyarakat yang pernah melakukan tradisi mangaku induak. Teknik pengumpulan data dalam penelitian ini yaitu melalui wawancara, observasi, dan dokumentasi.

Dalam proses penelitian, peneliti menggunakan alat perekam, kamera, dan buku catatan. Dalam menguji keabsahan data tersebut, peneliti menggunakan teknik triangulasi sumber guna membandingkan informasi yang didapat dari informan-informan yang telah diwawancara dan yang diamati peneliti selama di lapangan mengenai tradisi mangaku induak dalam perkawinan.

Selanjutnya

peneliti

menganalisis data yang telah penulis peroleh di lapangan dan mereduksi data tersebut (memilih data yang benar-benar berkaitan dengan topik penelitian). Lalu peneliti menyajikan data hasil penelitian tersebut dalam bentuk naratif yang dapat dipahami pembaca, kemudian melakukan verifikasi serta menarik kesimpulan dari hasil penelitian tersebut.

\section{HASIL DAN PEMBAHASAN}

Proses mangaku induak dilakukan dalam bentuk upacara adat yang wajib dilaksanakan dengan memenuhi segala persyaratan tertentu yang telah ditetapkan adat. Menurut Fitri Eriyanti (2007) pelaksanaan dalam penyerahan syarat-syarat ini disebut dengan istilah "cupak diisi, limbago dituang". Adapun syaratsyarat yang harus dipenuhi oleh pendatang dalam melakukan mangaku induak dalam perkawinan tersebut tergantung pada adat kebiasaan yang sudah berlaku di masing-masing daerah karena hal tersebut ditetapkan oleh semua penghulu suku yang ada di daerah tersebut.

Menurut Leni Syafyahya,dkk (2016) syarat merupakan suatu tuntutan atau permintaan yang harus dipenuhi. Dengan kata lain, apabila tuntutan telah dipenuhi maka permintaan pun telah dikabulkan. Begitu pula, dengan permintaan suku bagi kaum yang meminta suku dan anak tidak bersuku. Suku akan didapatkan apabila tuntutan adat telah dipenuhi sesuai dengan pepatah adat "Cupak diisi limbago dituang" artinya ada aturan tersendiri untuk memenuhi suatu kewajiban pada keadaan yang berbeda-beda.

Berbicara mengenai proses maka tidak terlepas dari tahapan-tahapan pra pelaksanaan hingga pelaksanaannya. Adapun tahap pra pelaksanaannya yaitu:

Pendatang mendatangi orang tua dan mamak tempat mangaku induak.

a. Pendatang harus mendatangi rumah orang tua tempatnya akan mangaku induak guna memperkenalkan diri, meminta persetujuan calon orang tua tempatnya akan mangaku induak, selain itu calon orang tua angkat tersebut yang memberitahukan tentang syarat-syarat yang harus dipenuhi untuk mangaku induak tersebut. Setelah disetujui lalu mamak dikaciak gadang bapangku membawa pendatang tersebut kerumah mamak dan diperkenalkan nama, asal, dan sukunya serta dijelaskan bahwa pendatang ini akan mangaku induak ke suku tersebut. Setelah itu mamak yang akan menentukan waktu pelaksanaanya. 
b. Mengundang ibu-ibu setempat guna memasak hidangan untuk acara pelaksanaannya.

Sementara itu tahap pelaksaannya yaitu terdiri dari:

\section{Tahap pelaksanaan secara adat}

Pada saat malam pelaksanaan mangaku induak ini maka yang diundang yaitu masyarakat, mamakmamak dikaciak gadang babangku dalam suku tempat pendatang akan mangaku induak tersebut. Seluruh mamak-mamak nan gadang dari seluruh suku yang ada di Lubuk Malako, tukampuang, Tunganai, labai, datuak dan lengkap semuanya. Adapun aturan duduk dalam melakukan doa mangaku induak ini yaitu mamak harus mendampingi calon kemenakannya dan duduk disebelahnya. Dengan artian memperagakan kepada semua tamu yang hadir dan mengatakan bahwa telah mendapatkan anak kemenakan baru agar semua orang nagari tau bahwa pendatang tersebut adalah anak kemenakannya.

Kemudian dilanjutkan dengan membayar siriah panampan yang ada di dalam carano ale basak. Carano tersebut berisikan gambir, pinang, sadah, tembakau. Permintaan dalam carano ale basah ini dikatakan bahwa pendatang ini tabang basitumpu di nagari asalnya, hinggok basicangkam di Nagari Lubuk Malako, pai ditinggaan induak dan datang ke Lubuk Malako ditampati induak, ikolah tampek marapeknyo dirumah tempat ia mangaku induak. Selanjutnya dilakukanlah doa mangaku induak dan acara makan bersama bagi tamu yang hadir sebagai penutup acara pelaksaan mangaku induak secara adat.
Tahap pelaksanaan secara pusako mudo

Pusako mudo ini sama dengan perkenalan dengan yang muda-muda, dalam melakukan pusako mudo ini juga menggunakan sirih dan carano. Adapun syarat melakukan pusako mudo yaitu pendatang tersebut harus membawa rokok, air teh atau air kopi secukupnya, dan pisang 1 tajang. Dalam melakukan pusako mudo maka diundanglah semua ketua pemuda di masing-masing jorong dan diinformasikan juga kepada seluruh pemuda bahwa ada yang akan melakukan mangaku induak. Acara pusako mudo dilakukan di galanggang nan rami, maksudnya tempat-tempat perkumpulan pemuda Lubuk Malako.

Disana pendatang juga diperkenalkan dan dikatakan bahwa pendatang sudah menjadi kamanakan dari mamak suku tempatnya mangaku induak serta disebutkan tujuannya oleh mamak. Kemudian diserahkan oleh mamak kepada pemuda agar "kok kailia nak samo kailia jo nan basamo, kok ka mudiak nak samo jo nan basamo, jadi kok kaaie nak samo basa kalua nak samo kariang, jadi saadat jo sapamakai jo pemuda di Lubuk Malako" artinya apapun adat yang dipakai pemuda Lubuk Malako maka adat tersebut juga yang dipakai oleh pendatang tersebut karena dia telah resmi menjadi kemenakan mamak Lubuk Malako. Hal tersebut dilakukan untuk mendapatkan suku dan diakui oleh masyarakat sehingga pendatang dapat melangsungkan pernikahan di Lubuk Malako.

Setelah melakukan semua prosesi mangaku induak, maka pendatang telah resmi menjadi anggota suku 
tempatnya mangaku induak. Kemudian dia telah sama dengan anak kamanakan datuak di suku tadi jadi "malompek alah samo patah, manyuwak alah samo bungkuak" dimanapun orang melakukan kerja sosial mereka yang telah mangaku induak tersebut harus ikut, kalau ada iuran-iuran dalam membangun rumah gadang mereka harus ikut. Dalam setiap tahap pelaksanaan terlihat bahwa masyarakat Lubuk Malako menjunjung tinggi nilai gotong royong. Hal tersebut dilakukan dalam mencari maupun membuat sesuatu apa saja yang diperlukan dalam prosesi mangaku induak dalam perkawinan ini.

\section{KESIMPULAN}

Proses mangaku
dilaksanakan di rumah tempat
pendatang akan mangaku induak.
Tatacara proses mangaku induak
tersebut terdiri dari proses pra
pelaksanaan yaitu mendatangi orang
tua dan mamak-mamak tempat
tujuannya mangaku induak,
kemudian mengundang ibu-ibu
masyarakat setempat guna mambantu
membuat hidangan. Proses
pelaksanaan yaitu pelaksanaan secara
adat dan pelaksanaan secara Pusako
mudo.

\section{DAFTAR PUSTAKA}

Andayani Listyawati dan Akhmad Purnama. 2020. "Implementasi Nilai Kesetiakawanan Sosial dalam Tradisi Sewu Ingkung Implementation of Social Solidarity Values in the Sewu Ingkung Tradition". Jurnal PKS, Vol 19. No 1.
Atikah, Zahratul, dkk. 2019 “Tradisi Malakok dan Implikasinya terhadap Kehidupan Sosial Masyarakat Tambun Ijuak Kecamatan Payakumbuh Kabupaten 50 Kota". Journal of Civic Education (ISSN: 2622237X). Vol 2. No 5.

Eriyanti, Fitri.2007. "Malakok: Suatu Mekanisme Pendamai Ala Minangkabau". Jurnal DEMOKRASI. Vol VI. No 2.

Eriyanti, Fitri.2016. Malakok: Multicultural Concepts Based On Local Wisdow In Minangkabau Community. Jurnal Integration and Interconnection of Sciences "The Reflection of Islam Kaffah".

Sefriyono. 2015. "MALAKOK: Model Menegosiasikan Keragaman bagi Etnis Nias-Kristen dan Minangkabau-Islam di Kabupaten Padang Pariaman". Jurnal Penelitian \& Pengabdian. Vol 3. No 2.

Syafyahya, Leny, dkk. 2016. "Malakok sebagai Dasar Integrasi oleh Etnis Minangkabau di Kabupaten Dharmasraya Provinsi Sumatra Barat". Majalah Ilmiah Bahasa dan Sastra. Vol 13. No 2.

Yusrizal., Darfian Petra., \& Nurharmi. 2016. “Tradisi Mangaku induak dan Manimbang Salah dalam Perkawinan di Nagari Taratak Baru Kecamatan Tanjung Gadang Kabupaten Sijunjung". Jurnal FKIP. Universitas Bung Hatta. Vol 5. No 11 